\title{
The Role of Motivation in Online Professional Learning Strategies
}

\author{
Dr. Minseong Kim, Ph.D. \\ Louisiana State University Shreveport \\ Dr. Tami L. Knotts, D.B.A. \\ Louisiana State University Shreveport \\ Dr. Nancy D. Albers, Ph.D. \\ Louisiana State University Shreveport
}

\begin{abstract}
The importance of online learning has been highlighted by higher education, and online program administrators have looked for management strategies to establish competitive advantages through student satisfaction and loyalty. This research investigated the roles of various learning motivations (i.e., autonomous motivation, external motivation, need achievement, goal setting, social comparison, and reinforcement), perceived value, and satisfaction to predict students' loyalty toward an online program in the MBA context. Data were collected from online panel members of Qualtrics who were currently enrolled in online MBA programs in the United States. The empirical findings identify that perceived value was significantly influenced by external motivation, need achievement, goal setting, and reinforcement. MBA program satisfaction was positively affected by need achievement and reinforcement, and loyalty toward an MBA program was significantly influenced by perceived value and MBA program satisfaction. Overall, these results indicate the relative importance of each learning motivation for predicting online students' loyalty.
\end{abstract}

Keywords: e-learning, motivation, online program, MBA, loyalty

Categorizations: Education, Quantitative, Business Education

\section{Introduction}

$\mathrm{O}$ nline learning has been increasingly popular in higher education by providing students with university degree programs, professional certificate programs, and webinar series in the last decade. Both practitioners and scholars have attempted to formulate management strategies for online learning programs in higher education as the number of students who register for these programs has dramatically increased (i.e., 2,974,836 enrolled exclusively online in 2016 vs. 3,104,879 in 2017 and 3,325,750 enrolled in some online courses in 2016 vs. 3,352,581 in 2017) (Inside Higher ED, 2018). For example, using descriptive analysis, the 2019 Online Education Trends Report explores online students' goals, learning expectations, experiences, and reasons for selecting online learning options instead of oncampus programs (i.e., the program reputation, current situations, employer partnership, etc.).

In addition to industry reports, empirical academic research has been conducted to explore the role of student motivation in online learning programs. For instance, based on motivation theories, Lin, Zhang, and Zhang (2017) investigated the impacts of intrinsic and extrinsic motivations on satisfaction, 
perceived progress, and final grades among students attending virtual schools. Chen and Jang (2010) emphasized self-determination theory when they also explored the influences of extrinsic, intrinsic, identified, and introjected motivations on course satisfaction, perceived learning, engagement, and achievement. Prior studies have employed different theoretical frameworks for online students' learning motivation and have predicted similar outcomes, although they have, interestingly, indicated inconsistent results, depending on the dimensionality of the learning motivation construct (e.g., no significant relationship between motivation and satisfaction vs. direct or indirect association between motivation and satisfaction) (see Chen \& Jang, 2010; Hanus \& Fox, 2015; Lin et al., 2017; Yilmaz, 2017).

The differences enable scholars to formulate the following question: What theoretical background and dimensions of learning motivation are the best theory and triggers of favorable outcomes in the online learning setting (e.g., high levels of perceived value, satisfaction, and loyalty toward the online program)? For example, does self-determination theory that focuses on intrinsic (i.e., needs based) and extrinsic aspects (i.e., rewards based) explain online students' learning motivation the same as those of traditional students? Needs-based and rewards-based motivations have been primarily studied by prior research to explain and predict online students' performance and outcomes (Barak, Watted, \& Haick, 2016; Zhou, 2016), but it is also important to consider the characteristics of the online learning environment, such as social-based motivation (i.e., social comparison), to formulate the most appropriate model that predicts the students' perceived value, satisfaction, and loyalty toward an online program (Rogers, 2017). More specifically, although the online learning platform does not provide students with face-to-face interpersonal interactions, it functions as a unique setting for unlimited socialization for students via virtual cooperation, discussion, chatting, competition, and video calls with other classmates to successfully complete their projects and courses (Yanson \& Johnson, 2016). Online programs have also used social networking platforms for marketing purposes and as a virtual place to build a social connection between former students and current/future students under a more natural setting.

In addition to the aforementioned theories in the education field, prior research in the context of classroom and traditional learning has documented well developed motivation-based theories to predict student performance, satisfaction, and behavioral intention, such as expectancy-value (Wigfield \& Eccles, 2000) and reinforcement (Coetzer, 2007). Little research to date, however, has investigated integration of theoretical frameworks for an online professional program (e.g., graduate degree and certificate) to predict favorable outcomes from a broader perspective on online students' learning motivation.

This study fills the academic gap by focusing on a wide range of motivational factors (i.e., based on self-determination, need achievement, goal setting, social comparison, and Skinner's reinforcement theories) that influence perceived value, satisfaction, and loyalty among online MBA students (Atkinson \& Litwin, 1960; Bandura, 1977; Deci \& Ryan, 2008; Festinger, 1954; Locke, Shaw, Saari, \& Latham, 1981; Skinner, 1957; Vansteenkiste, Lens, De Witte, \& Feather, 2005). The empirical result will address which motivation is the most influential predictor of favorable outcomes for online professional learning management. The existing literature on online students' motivation framework will be extended with the integration of socially based motivation and an examination of which motivation is a better driver of perceived value and satisfaction, respectively, which in turn establish loyalty among online students. This study formulates managerial implications for online professional programs in addition to its theoretical implication.

\section{Self-Determination Theory}

Theoretical Background

The fundamental notion of self-determination theory is that individuals have inherent tendencies toward optimal development and continuous growth that make them active (Deci \& Ryan, 2000). The inherent tendencies are divided into intrinsic and extrinsic motivations. First, intrinsic motivation plays a role in individuals' psychological function for continuous growth. For example, students with a high level 
of intrinsic motivation are more likely to engage in learning-related activities for the sake of the learning experience without consideration of other consequences (Clements \& Kamau, 2018). Students pursuing optimal development are also involved in how to take extrinsic motivations (or external benefits) from a class by adapting to its learning environment (Deci \& Ryan, 2000). Self-determination theory assumes that both intrinsic and extrinsic motivations are based on individuals' psychological needs for relatedness (i.e., a sense of belonging with other students and/or feeling of connection with other students), competence (i.e., belief in how well the learning environment supports students in producing their desired outcomes), and autonomy (i.e., a sense of ownership of students' behavior) (Deci \& Ryan, 2008).

Self-determination theory focuses more on the process of autonomy support than the other two needs do because those needs are primarily associated with the social aspect (Clements \& Kamau, 2018). More specifically, autonomy support emphasizes students, such as their sense of self-initiation, being allowed to have freedom and choice to engage in various learning-related activities. When students are satisfied with autonomy support, their intrinsic motivation for learning increases (Richter, Raban, \& Rafaeli, 2015). Conversely, extrinsic motivation in education is based on tangible incentives, such as higher levels of salary, degree, or social achievements (e.g., occupation). However, depending on their intrinsic needs, each student tends to consider different incentives as rewarding (Deci, Vallerand, Pelletier, \& Ryan, 1991).

\section{Need Achievement Theory}

Need achievement theory assumes that individuals with a high level of achievement are more likely to desire success by exhibiting high ability while performing a task (Nicholls, 1984). Hence, achieving success can serve as a motivational factor for learning among students. For example, students with high achievement motivation tend to prefer tasks of intermediate or high difficulty to gain an opportunity to use and enhance their ability (Richter et al., 2015). In particular, the online learning environment provides students with clear status indicators and achievement systems that enable them to monitor their performance. For example, compared to traditional classes, online classes should be well--structured for the first week of each semester by providing achievement systems that indicate each goal of all modules. The need for achievement enables students to concentrate on learning and achieve the learning goals properly (Sitanggang, Luthan, \& Dwiyanto, 2020). Online students can also quickly and visibly check their progression more easily and frequently than traditional students. The progress checking approach serves as an indicator that directs students to achieve their learning goals (Moneta, 2011). Furthermore, the time and place flexibility of online classes can extend students' study time by offering various ways to consume the course content and achieve each module's objectives. This characteristic of online learning environments makes students strive hard to succeed in each course.

\section{Goal Setting Theory}

A goal is the aim or object of an action and refers to what individuals attempt to accomplish (Locke et al., 1981). According to the goal setting theory, individuals tend to be motivated to achieve more by difficult, immediate, context appropriate, and specific goals than by long-term goals (Richter et al., 2015). The assumption is based on the notion that short-term goals enable individuals to focus their effort on things requiring present, direct attention and to increase their persistence and belief in completing an ongoing task (Locke et al., 1981). Hence, goal setting leads students to improve their academic performance when (1) their goals are sufficiently challenging and specific rather than general; (2) they can see their progress with respect to the goal via feedback; and (3) they believe that they have sufficient ability to achieve the goals (i.e., self-efficacy) (Bandura \& Locke, 2003; Locke et al., 1981; Richter et al., 2015). For example, a high level of that belief leads students to set more ambitious goals and enhance their academic performance in class (Clements \& Kamau, 2018). This is because students with more ambitious goals set themselves the most challenging tasks to perform better in class than others do (Elliot, 
McGregor, \& Gable, 1999). The goal commitment to learning is a motivational factor that enables students to develop appropriate skills and/or strategies and increase persistence to complete the challenging tasks and achieve the goals by emphasizing success seeking (Clements \& Kamau, 2018).

\section{Social Comparison Theory}

Social comparison theory assumes that individuals tend to accumulate knowledge about themselves by continuously comparing themselves with others (Festinger, 1954). In addition to knowledge about themselves, individuals keep evaluating and comparing their reactions, abilities, and beliefs to those of similar others because they want to check and improve their ability (Lillienfeld, Lynn, Namy, \& Woolf, 2009). They wish, consequently, to gain a better position than that of similar others. Thus, this type of student tends to be more competitive and interested in the learning environment than other students through an upward comparison (Richter et al., 2015). The upward comparison means that students compare themselves with others who are better they are. The upward comparison triggers the students' self-improvement motivation to increase their self-evaluation of competence and their belief in getting a better position than others in class (Wolff, Helm, \& Möller, 2018; Wood, 1989).

The online environment particularly displays other students' progress and academic performance through discussion forums and class averages. The online system environment allows students to recognize whether they achieve a higher score or the highest score in each assignment or course by comparing their score to other students' work and the class average. Students can also monitor others' academic performance so they can evaluate whether their current academic performance is worse or better than the others and determine what they should do to improve their competition in class. This learning environment leads to friendly competition among people and makes them take on the challenging tasks to perform better than others (Medler \& Magerko, 2011; Wolff et al., 2018).

\section{Reinforcement Theory}

The reinforcement theory proposed by Skinner (1957) considers reinforcement as an outcome that strengthens the probability of a response. Hence, individuals tend to be motivated to take an action depending on whether the outcome is positive or negative. Accordingly, the fundamental notion of the theory is that reinforcement triggers individuals to continuously establish a desirable behavior in a positive or negative manner. For example, when reinforcement is gone, individuals' desired behavior tends to gradually weaken and eventually be extinguished (Richter et al., 2015). In other words, if there is a positive correlation between individuals' behaviors and their consequences, those individuals are more likely to be motivated to behave to get the results. However, they are less likely to behave and may even cease action when their behavior leads to negative or neutral outcomes (Scott, 2018). Reinforcement particularly serves as a motivational factor for students in learning environments, because learning provides them with psychological rewards and incentives (e.g., development of personal skills and selfimprovement).

\section{Perceived Value, Satisfaction, and Loyalty}

Perceived value has been considered as a core antecedent of behavioral outcomes, such as satisfaction and loyalty (Prebensen \& Xie, 2017). Perceived value is defined as all of the quantitative and qualitative objective and subjective factors that comprise consumers' complete consumption experience (Zeithaml, 1988). Consumers categorize the factors into benefits and costs to evaluate whether product or service-benefits (e.g., quality, such as utilitarian functions) are greater than their costs (e.g., consumers' time and effort for consumption of the product/service as well as its price) based on their perception (Kim \& Thapa, 2018). In this study, students gain benefits from taking online courses, completing assignments, interacting with instructors, developing skills, and receiving a professional degree at reasonable prices and 
in a reasonable time. Students who pursue a higher degree also receive its high status and feel affiliated with a reputable institution as a consequence of enrolling in the program.

From the long-term perspective, satisfaction has an important role in generating loyalty, positive word-of-mouth, and sustainable profitability for service organizations (e.g., education service in this study) (Prebensen \& Xie, 2017). Satisfaction is a unidimensional construct that tends to be formed as a consequence of customers' aggregate judgement of all transactions and interactions with a product/service (Kim \& Thapa, 2018). Based on this notion, this study defines satisfaction as a unidimensional concept that reflects students' overall impressions with an MBA program regarding its education services (Sun, Tsai, Finger, Chen, \& Yeh, 2008).

Customer loyalty results in sustainable competitive advantages for any product/service and organization (Kim \& Thapa, 2018; Prebensen \& Xie, 2017). For example, a high level of loyalty toward a particular brand or product/service leads to customers' greater willingness to recommend the brand or product/service and a positive word-of-mouth intention as well as continuous usage intention and supportive behavior (Prebensen \& Xie, 2017). Hence, this study conceptualizes loyalty by focusing on the likelihood that students will recommend their online MBA program to others and keep supporting the program after graduation through donations and mentorship.

\section{Hypotheses Development}

The main purpose of this research is to fill the academic gap in the online program (or elearning) management literature by exploring the roles of various motivation factors in predicting students' perceived value, program satisfaction, and loyalty toward the program. This study applies each motivation theory to the online MBA program context by applying self-determination theory (Deci \& Ryan, 2000), need achievement theory (Nicholls, 1984), goal setting theory (Locke et al., 1981), social comparison theory (Festinger, 1954), and reinforcement theory (Skinner, 1957) to explain which motivational factor is the most influential to favorable outcomes for online professional programs. This study considers perceived value and MBA program satisfaction as mediators in the paths from motivational factors to loyalty toward MBA programs based on the stimulus-organism-response (S-O-R) theory. The fundamental notion of the S-O-R theory is that a stimulus triggers the development of an organism's internal evaluation procedure, which leads to a response (Konuk, 2019). This study found that online professional program attributes, such as courses, assignments, instructors, and learning systems as stimuli, may affect internal evaluations of students (i.e., perceived value and program satisfaction in this study), which consequently increase their loyalty level toward the program (Tsiotsou,

2006). Students may evaluate a program as valuable and perceive it as satisfactory based on its attributes (Konuk, 2019). Therefore, this research provides meaningful insights for online program administrators and e-learning scholars as well as instructors who have been involved in online professional program development. This study establishes and tests the following research hypotheses:

H1: Autonomous motivation is positively associated with perceived value (H1a) and MBA program satisfaction (H1b). External motivation is positively associated with perceived value $(H 1 c)$ and $M B A$ program satisfaction $(\mathrm{H} 1 \mathrm{~d})$.

H2: Need achievement is positively associated with perceived value ( $\mathrm{H} 2 \mathrm{a})$ and MBA program satisfaction ( $\mathrm{H} 2 \mathrm{~b}$ ).

H3: Goal setting is positively associated with perceived value $(\mathrm{H} 3 \mathrm{a})$ and MBA program satisfaction (H3b).

H4: Social comparison is positively associated with perceived value (H4a) and MBA program satisfaction ( $\mathrm{H} 4 \mathrm{~b})$.

H5: Reinforcement is positively associated with perceived value ( $\mathrm{H} 5 \mathrm{a}$ ) and MBA program satisfaction (H5b).

KIM, KNOTTS, \& ALBERS/ DOI: 10.5929/2021.11.1.3 
H6: Perceived value is positively associated with MBA program satisfaction (H6a) and loyalty toward MBA program (H6b).

H7: MBA program satisfaction is positively associated with loyalty toward MBA program.

\section{Methodology}

\section{Sampling and Data Collection}

This study worked with Qualtrics (a web-based survey company) to recruit students who are enrolled in online MBA programs in the United States. Qualtrics' online panel samples help scholars to increase generalizability or external validity and to collect geographically/culturally diverse samples in the United States (Baek \& Yoo, 2018). First, a survey link was sent to active Qualtrics panel members who were currently enrolled in a 100\% online MBA program. The first data collection was completed with 215 panel members. The study's authors carefully reviewed each respondent's institution to confirm they offered a $100 \%$ online MBA program before finalizing the dataset. Thirty samples were consequently removed through this data purification process. The second data collection was conducted, and this study finally collected and used 210 samples for data analyses. Among the participants, 133 were female (63.3\%); $49.1 \%$ were in their thirties and forties followed by twenties (9.5\%); $34.8 \%$ of the sample worked in the machinery and equipment business followed by agribusiness (21.4\%), chemicals, energy, or environmental technology (11.9\%); $24.8 \%$ of the participants worked in their respective industries for around two years; and $13.3 \%$ had worked for around one year.

\section{Measures}

This study adapted survey items from previous studies to measure all constructs of the research model (see Table 1). A 7-point Likert-type scale was employed to measure all items from " 1 = strongly disagree" to "7 = strongly agree." The authors selected the measurements based on how well they had been theoretically developed and rigorously tested in prior studies. The survey items were finalized after several revisions. This study also employed a procedural remedy to control common method variance (e.g., response biases such as response formats, scale types, or social desirability) by randomly ordering some of the survey items in the finalized questionnaire (Bagozzi \& Yi, 1990).

\section{Results}

\section{Measurement Model}

The authors followed Anderson and Gerbing's (1992) two-step approach to test the reliability and validity of all measures before proceeding with a path analysis. First, Cronbach's alpha coefficients were assessed by SPSS 26.0 to check the reliability of all measures. As indicated in Table 1, Cronbach's alpha coefficients of all measures employed in this research were more than 0.70 that is generally acceptable in the social science field (Nunnally, 1978). Second, confirmatory factor analysis (CFA) was performed by AMOS 26.0 to assess the validity of all measures (Anderson \& Gerbing, 1992). During this stage, two items were dropped to maintain the convergent and discriminant validity of each construct.

As a result, the critical ratios of all measures were statistically significant (i.e., greater than $2.58, p<$ 0.01 ), signifying the convergent validity. 


\section{Table 1}

Measurement model from CFA

Constructs and Variables

Standardized Critical

loading

ratio

Autonomous motivation $(\alpha=0.798)$ from Graves, Sarkis \& Zhu (2013)

I have engaged in this MBA program because it allows me to achieve goals I consider important.

$0.727 \quad$ Fixed

I have engaged in this MBA program because it fits with my personal values.

$0.727 \quad 9.930$

I have engaged in this MBA program because it is personally important to me.

$0.762 \quad 10.402$

I have engaged in this MBA program because of the pleasure I get from it.

$0.639 \quad \underline{8.736}$

External motivation $(\alpha=0.759)$ from Graves et al. (2013)

$\begin{array}{lll}\text { I have engaged in this MBA program because it is required for my career path. } & 0.889 & \text { Fixed }\end{array}$

I have engaged in this MBA program because I was awarded for doing it. $\quad 0.420 \quad 4.800$

I am in this MBA program because I was paid to do it. ${ }^{*}$

Table 1 (continued)

Measurement model from CFA

\begin{tabular}{lcc}
\hline Constructs and Variables & $\begin{array}{c}\text { Standardized } \\
\text { loading }\end{array}$ & $\begin{array}{c}\text { Critical } \\
\text { ratio }\end{array}$ \\
\hline Need achievement $(\alpha=0.822)$ from Elliot \& Murayama (2008) & & \\
My aim is to completely master the materials presented in this MBA program. & 0.670 & Fixed \\
I am striving to understand the content of this MBA program as thoroughly as possible. & 0.720 & 9.197 \\
My goal is to learn as much as possible. & 0.765 & 9.686 \\
My aim is to perform well relative to other students. & 0.731 & 9.318 \\
I am striving to do well compared to other students. & 0.587 & 7.678 \\
My goal is to perform better than other students. ${ }^{*}$ & - & -
\end{tabular}

Goal setting ( $\alpha=0.744$ ) from Miller, Behrens, \& Greene (1993)

It was easy for me to establish learning goals for this MBA program.

$0.579 \quad$ Fixed

In studying for quizzes/tests, I was able to establish clear goals for my study time.

$0.769 \quad 8.090$

As I progressed through this MBA program, I had a clear idea of what I was trying to

$0.750 \quad 7.978$

accomplish.

Social comparison ( $\alpha=0.767$ ) from Gibbons \& Buunk (1999)

I often compare myself with others with respect to what I have accomplished in life.

$0.561 \quad$ Fixed

I often like to talk with others about mutual opinions and experiences.

$0.714 \quad 7.907$

If I want to learn more about something, I try to find out what others think about it.

0.676

7.637

Reinforcement ( $\alpha=0.834$ ) from Coetzer (2007)

I am in this MBA program to gain opportunities to learn different tasks.

$0.703 \quad$ Fixed

I am in this MBA program to gain opportunities to complete challenging tasks.

$0.751 \quad 10.424$

I am in this MBA program to gain opportunities to learn new skills.

$0.768 \quad 10.652$

I am in this MBA program to gain opportunities to improve myself.

$0.769 \quad 10.668$

Perceived value ( $\alpha=0.766)$ from Lee, Yoon, \& Lee (2007) Overall,

enrolling this MBA program is valuable and worth.

$0.666 \quad$ Fixed

KIM, KNOTTS, \& ALBERS/ DOI: 10.5929/2021.11.1.3 
The value I received by enrolling in this MBA program was more than I expected. $\quad 0.700 \quad 8.667$

I obtained good results from enrolling this MBA program.

$0.800 \quad 9.612$

MBA program satisfaction $(\alpha=0.796)$ from Kim \& Thapa (2018)

I am satisfied with what I have learned in this MBA program.

$0.696 \quad$ Fixed

I am satisfied with my personal development in this MBA program.

$0.787 \quad 10.219$

Overall, I am satisfied with this MBA program.

$0.778 \quad \underline{10.123}$

Loyalty toward MBA program ( $\alpha=0.835$ ) from Tsao \& Coll (2004)

I will use trending words such as hashtags for this MBA program while using social media.

$0.511 \quad$ Fixed

I will recommend this MBA program to others.

$0.750 \quad 7.058$

I will encourage other people to enroll in this MBA program.

$0.739 \quad 7.009$

I am interested in subscribing to a university newsletter after graduation.

$0.626 \quad 6.422$

I am interested in sharing experiences with future MBA students after graduation. $\quad 0.699 \quad 6.821$

$\begin{array}{ll}\text { After graduation, I am interested in donating money to support students. } & 0.597\end{array} 6.249$

I am interested in being an e-mail mentor for a future MBA student after graduation. $\quad 0.538$

[]$^{2}=1056.679$, d.f. $=491\left(\chi^{2} /\right.$ d.f. $\left.=2.152\right), p<0.001, \mathrm{IFI}=0.855, \mathrm{TLI}=0.831, \mathrm{CFI}=0.852, \mathrm{RMSEA}=0.074$

${ }^{*}$ Items were deleted during the confirmatory factor analysis.

This study performed multiple CFAs with each pair of primary measures to test the discriminant validity of all measures, following the approach of Rust, Moorman, and Dickson (2002). The chi-square and degree of freedom values of each unconstrained model were compared with those of each constrained model (i.e., set as the constructs are same). This statistical approach signifies discriminant validity between two constructs when the difference in the degree of freedom values between two models is 1 and the difference in the chi-square values between two models is more than $3.84(p<0.05)$. Table 2 accordingly demonstrated that all constructs used for this research had discriminant validity.

\section{Table 2}

Chi-square difference test for discriminant validity of the measures

\begin{tabular}{lrrrrrr}
\hline & \multicolumn{7}{c}{ Constrained } & \multicolumn{7}{c}{ Unconstrained } \\
\cline { 2 - 7 } & $\chi^{2}$ & $d f$ & $\chi^{2}$ & $d f$ & $\Delta \chi^{2}$ & $p^{*}$ \\
\hline Autonomous motivation vs. External motivation & 26.641 & 9 & 22.518 & 8 & 4.123 & 0.042 \\
Autonomous motivation vs. Need achievement & 57.489 & 27 & 48.232 & 26 & 9.257 & 0.002 \\
Autonomous motivation vs. Goal setting & 31.948 & 14 & 19.186 & 13 & 12.762 & 0.000 \\
Autonomous motivation vs. Social comparison & 20.519 & 14 & 14.477 & 13 & 6.042 & 0.014 \\
Autonomous motivation vs. Reinforcement & 55.141 & 20 & 42.277 & 19 & 12.864 & 0.000 \\
Autonomous motivation vs. Perceived value & 48.270 & 14 & 34.179 & 13 & 14.091 & 0.000 \\
Autonomous motivation vs. MBA program satisfaction & 32.834 & 14 & 18.675 & 13 & 14.159 & 0.000 \\
Autonomous motivation vs. Loyalty toward MBA & & & & & & \\
program & 165.983 & 44 & 155.431 & 43 & 10.552 & 0.000 \\
External motivation vs. Need achievement & 24.742 & 14 & 18.293 & 13 & 6.449 & 0.011 \\
External motivation vs. Goal setting & 20.734 & 5 & 10.207 & 4 & 10.527 & 0.001 \\
External motivation vs. Social comparison & 7.233 & 5 & 2.374 & 4 & 4.859 & 0.028 \\
External motivation vs. Reinforcement & 26.829 & 9 & 19.603 & 8 & 7.226 & 0.007
\end{tabular}

KIM, KNOTTS, \& ALBERS/ DOI: 10.5929/2021.11.1.3 


\begin{tabular}{|c|c|c|c|c|c|c|}
\hline External motivation vs. Perceived value & 22.525 & 5 & 15.985 & 4 & 6.540 & 0.011 \\
\hline External motivation vs. MBA program satisfaction & 10.156 & 5 & 1.613 & 4 & 8.543 & 0.003 \\
\hline External motivation vs. Loyalty toward MBA program & 139.012 & 27 & 133.061 & 26 & 5.951 & 0.015 \\
\hline Need achievement vs. Goal setting & 46.401 & 20 & 29.733 & 19 & 16.668 & 0.000 \\
\hline Need achievement vs. Social comparison & 44.851 & 20 & 37.689 & 19 & 7.162 & 0.007 \\
\hline Need achievement vs. Reinforcement & 64.938 & 27 & 58.276 & 26 & 6.662 & 0.010 \\
\hline Need achievement vs. Perceived value & 63.091 & 20 & 49.605 & 19 & 13.486 & 0.000 \\
\hline Need achievement vs. MBA program satisfaction & 57.206 & 20 & 45.679 & 19 & 11.527 & 0.001 \\
\hline Need achievement vs. Loyalty toward MBA program & 181.192 & 54 & 166.487 & 53 & 14.705 & 0.000 \\
\hline Goal setting vs. Social comparison & 18.939 & 9 & 12.686 & 8 & 6.253 & 0.012 \\
\hline Goal setting vs. Reinforcement & 62.576 & 14 & 52.001 & 13 & 10.575 & 0.001 \\
\hline Goal setting vs. Perceived value & 29.327 & 9 & 13.611 & 8 & 15.716 & 0.000 \\
\hline Goal setting vs. MBA program satisfaction & 24.931 & 9 & 8.698 & 8 & 16.233 & 0.000 \\
\hline Goal setting vs. Loyalty toward MBA program & 140.504 & 35 & 128.838 & 34 & 11.666 & 0.001 \\
\hline Social comparison vs. Reinforcement & 33.551 & 14 & 28.910 & 13 & 4.641 & 0.031 \\
\hline Social comparison vs. Perceived value & 16.240 & 9 & 5.903 & 8 & 10.337 & 0.001 \\
\hline Social comparison vs. MBA program satisfaction & 23.444 & 9 & 15.122 & 8 & 8.322 & 0.004 \\
\hline Social comparison vs. Loyalty toward MBA program & 129.301 & 35 & 121.468 & 34 & 7.833 & 0.005 \\
\hline Reinforcement vs. Perceived value & 52.278 & 14 & 43.108 & 13 & 9.170 & 0.002 \\
\hline Reinforcement vs. MBA program satisfaction & 59.839 & 14 & 48.637 & 13 & 11.202 & 0.001 \\
\hline Reinforcement vs. Loyalty toward MBA program & 175.521 & 44 & 165.119 & 43 & 10.402 & 0.001 \\
\hline Perceived value vs. MBA program satisfaction & 29.184 & 9 & 19.479 & 8 & 9.705 & 0.002 \\
\hline Perceived value vs. Loyalty toward MBA program & 163.613 & 35 & 148.732 & 34 & 14.881 & 0.000 \\
\hline $\begin{array}{l}\text { MBA program satisfaction vs. Loyalty toward MBA } \\
\text { program }\end{array}$ & 169.208 & 35 & 157.243 & 34 & 11.965 & 0.001 \\
\hline
\end{tabular}

Finally, this study conducted Harman's one-factor test as a statistical remedy, in addition to the procedural remedy, to empirically check whether common method variance was a serious issue (Podsakoff \& Organ, 1986). It can be concluded that common method variance is a serious threat in a study if the chi-square and degree of freedom values of a single factor measurement model are better than those of a multidimensional model. The empirical finding indicated (1) chi-square $=1,056.679$ with $\mathrm{df}=491$ (the measurement model) and (2) chi-square $=1,351.446$ with $\mathrm{df}=527$ (the one-factor model). Based on the finding, this study concluded that common method variance was successfully controlled.

\section{Testing of the Research Hypotheses}

The authors calculated the means of all measures for each construct to perform a path analysis via AMOS 26.0 after confirming the reliability and validities of all measures. The fit indices of the research model are indicated under Table 3. Figure 1 also illustrates maximum likelihood estimates (MLE) for the proposed model's parameters. 


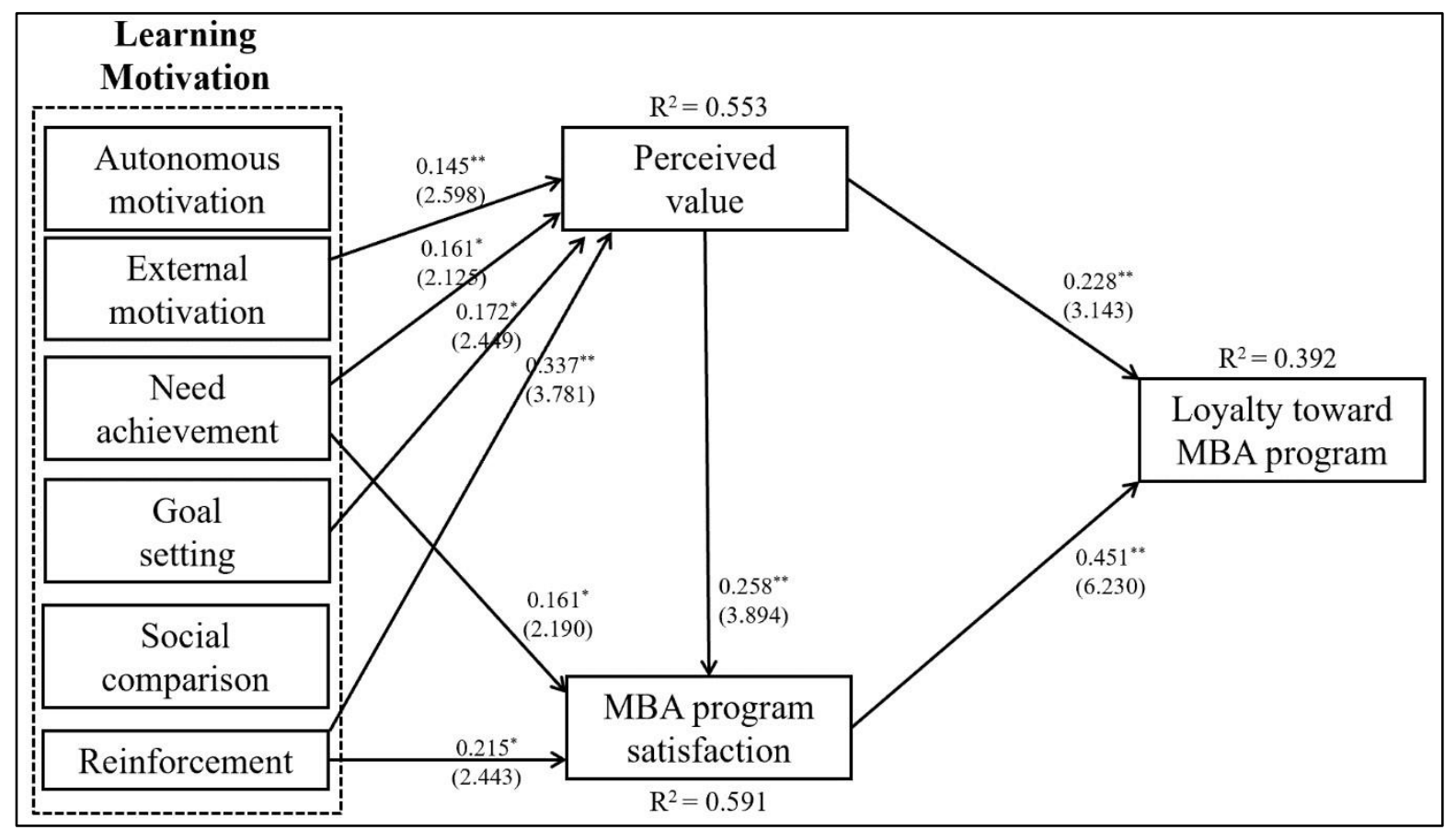

Figure 1. Estimates of path analysis

${ }^{* *} p<0.01,{ }^{*} p<0.05$. Note: Only significant paths are demonstrated.

$\mathrm{H} 1 \mathrm{a}$ and H1b indicated online MBA students' autonomous motivation would positively affect perceived value and MBA program satisfaction. However, its impacts on perceived value (coefficient = 0.074 , critical ratio $=1.001, p>0.05$ ) and MBA program satisfaction (coefficient $=0.054$, critical ratio $=$ $0.766, p>0.05$ ) were not statistically significant, not supporting $\mathrm{H} 1 \mathrm{a}$ and $\mathrm{H} 1 \mathrm{~b}$. $\mathrm{H} 1 \mathrm{c}$ and $\mathrm{H} 1 \mathrm{~d}$ also addressed whether online MBA students' external motivation would positively influence perceived value and MBA program satisfaction. External motivation's influence on perceived value was statistically significant (coefficient $=0.145$, critical ratio $=2.598, p<0.01$ ) but not on MBA program satisfaction (coefficient $=$ 0.022 , critical ratio $=0.404, p>0.05$ ), supporting $\mathrm{H} 1 \mathrm{c}$ only. $\mathrm{H} 2 \mathrm{a}$ and $\mathrm{H} 2 \mathrm{~b}$ speculated that online MBA students' need achievement would positively affect perceived value and MBA program satisfaction. Need achievement's influences on perceived value (coefficient $=0.161$, critical ratio $=2.125, p<0.05$ ) and MBA program satisfaction (coefficient $=0.161$, critical ratio $=2.190, p<0.05$ ) were statistically significant, supporting $\mathrm{H} 2 \mathrm{a}$ and $\mathrm{H} 2 \mathrm{~b}$.

$\mathrm{H} 3 \mathrm{a}$ and $\mathrm{H} 3 \mathrm{~b}$ proposed positive associations between online MBA students' goal setting and perceived value/MBA program satisfaction. The impact on perceived value (coefficient $=0.172$, critical ratio $=2.449, p<0.05$ ) was statistically significant but not on MBA program satisfaction (coefficient $=$ 0.099 , critical ratio $=1.461, p>0.05$ ), supporting $\mathrm{H} 3 \mathrm{a}$ only. Additionally, $\mathrm{H} 4 \mathrm{a}$ and $\mathrm{H} 4 \mathrm{~b}$ indicated online MBA students' social comparison would positively affect perceived value and MBA program satisfaction. However, the influences on perceived value (coefficient $=0.001$, critical ratio $=0.014, p>0.05$ ) and MBA program satisfaction (coefficient $=0.094$, critical ratio $=1.274, p>0.05$ ) were not statistically significant. However, $\mathrm{H} 6 \mathrm{a}$ and $\mathrm{H} 6 \mathrm{~b}$ regarding the positive associations between online MBA students' reinforcement and perceived value (coefficient $=0.337$, critical ratio $=3.781, p<0.01$ ) $/ \mathrm{MBA}$ program satisfaction (coefficient $=0.215$, critical ratio $=2.443, p<0.05$ ) were supported. Lastly, $\mathrm{H} 6$ and $\mathrm{H} 7$ addressed the positive relationships among online MBA students' perceived value, MBA program satisfaction, and loyalty towards an MBA program. Perceived value had significantly positive influences on MBA program satisfaction (coefficient $=0.258$, critical ratio $=3.894, p<0.01$ ) and loyalty toward MBA program (coefficient $=0.228$, critical ratio $=3.143, p<0.01$ ), supporting $\mathrm{H6a}$ and $\mathrm{H} 6 \mathrm{~b}$. MBA program satisfaction 
also had a significantly positive impact on loyalty towards an MBA program (coefficient $=0.451$, critical ratio $=6.230, p<0.01$ ), supporting $\mathrm{H} 7$.

In addition to their direct impacts, this study tested the indirect impacts of online MBA students' motivations on loyalty toward their MBA program through perceived value and MBA program satisfaction. Based on the Monte Carlo and Bootstrap maximum likelihood approaches, the indirect effects were assessed within $95 \%$ of confidence level (Kim \& Kim, 2020). Table 3 indicated that online

MBA students' loyalty toward their MBA program was significantly influenced only by need achievement (indirect coefficient $=0.128, p<0.01$ ), goal setting (indirect coefficient $=0.104, p<0.05$ ), and reinforcement (indirect coefficient $=0.213, p<0.01$ ) through mediators, such as perceived value and MBA program satisfaction.

\section{Table 3}

Standardized parameter estimates

\begin{tabular}{|c|c|c|c|}
\hline Path & $\begin{array}{l}\text { Standardized } \\
\text { estimates }\end{array}$ & $\begin{array}{l}\text { Standardized } \\
\text { error }\end{array}$ & $\begin{array}{c}\text { Critical } \\
\text { ratio }\end{array}$ \\
\hline Autonomous motivation $\rightarrow$ Perceived value & 0.074 & 0.080 & 1.001 \\
\hline Autonomous motivation $\rightarrow$ MBA program satisfaction & 0.054 & 0.077 & 0.766 \\
\hline External motivation $\rightarrow$ Perceived value & 0.145 & 0.051 & $2.598^{* *}$ \\
\hline External motivation $\rightarrow$ MBA program satisfaction & 0.022 & 0.050 & 0.404 \\
\hline Need achievement $\rightarrow$ Perceived value & 0.161 & 0.082 & $2.125^{*}$ \\
\hline Need achievement $\rightarrow$ MBA program satisfaction & 0.161 & 0.080 & $2.190^{*}$ \\
\hline Goal setting $\rightarrow$ Perceived value & 0.172 & 0.070 & $2.449^{*}$ \\
\hline Goal setting $\rightarrow$ MBA program satisfaction & 0.099 & 0.069 & 1.461 \\
\hline Social comparison $\rightarrow$ Perceived value & 0.001 & 0.075 & 0.014 \\
\hline Social comparison $\rightarrow$ MBA program satisfaction & 0.094 & 0.073 & 1.274 \\
\hline Reinforcement $\rightarrow$ Perceived value & 0.337 & 0.087 & $3.781^{* *}$ \\
\hline Reinforcement $\rightarrow$ MBA program satisfaction & 0.215 & 0.087 & $2.443^{*}$ \\
\hline Perceived value $\rightarrow$ MBA program satisfaction & 0.258 & 0.067 & $3.894^{* *}$ \\
\hline Perceived value $\rightarrow$ Loyalty toward MBA program & 0.228 & 0.072 & $3.143^{* *}$ \\
\hline MBA program satisfaction $\rightarrow$ Loyalty toward MBA program & 0.451 & 0.071 & $6.230^{* *}$ \\
\hline Indirect effects & Standardize & estimates & $p$-value \\
\hline Autonomous motivation $\rightarrow$ Loyalty toward MBA program & & & 0.216 \\
\hline External motivation $\rightarrow$ Loyalty toward MBA program & & & 0.079 \\
\hline Need achievement $\rightarrow$ Loyalty toward MBA program & & & $0.003^{* *}$ \\
\hline Goal setting $\rightarrow$ Loyalty toward MBA program & & & $0.011^{*}$ \\
\hline Social comparison $\rightarrow$ Loyalty toward MBA program & & & 0.319 \\
\hline Reinforcement $\rightarrow$ Loyalty toward MBA program & & & $0.001^{* *}$ \\
\hline Endogenous variables & & \multicolumn{2}{|l|}{$\operatorname{SMC}\left(R^{2}\right)$} \\
\hline Perceived value & & \multicolumn{2}{|c|}{$0.553(55.3 \%)$} \\
\hline MBA program satisfaction & & \multicolumn{2}{|c|}{$0.591(59.1 \%)$} \\
\hline Loyalty toward MBA program & & \multicolumn{2}{|c|}{$0.392(39.2 \%)$} \\
\hline
\end{tabular}

${ }^{\mathrm{a}} \mathrm{g}^{2}=47.852$, d.f. $=6\left(\chi^{2} /\right.$ d.f. $\left.=7.975\right), p<0.004, \mathrm{IFI}=0.968, \mathrm{TLI}=0.800, \mathrm{CFI}=0.967, \mathrm{SRMR}=0.073$ 


\section{Discussion}

\section{Theoretical Implications}

This research adapted various learning motivation theories and frameworks to explore the determinants of management outcomes for an online professional program, such as perceived value, MBA program satisfaction, and loyalty toward MBA program (Pham, Limbu, Bui, Nguyen, \& Pham, 2019). First, this study contributes to the existing online learning literature by proposing an integrated model that predicts students' loyalty toward a professional program with an empirical emphasis on the broader perspectives on internal motivations. In the educational technology and online learning management literature, external or situational factors have been considered primarily to predict student satisfaction and loyalty, such as service quality, technical system quality, support system quality, and instructor quality (Al-Fraihat, Joy, Masa'deh, \& Sinclair, 2020; Pham et al., 2019). However, the external or situational factors, from the psychological perspective, tend to be more unstable and more easily influenced by other factors than internal motivations among individuals (Deci \& Ryan, 2008). Additionally, from the educational standpoint, students with higher levels of internal learning motivations are less likely to be influenced by external or situational factors by concentrating on achievement-relevant outcomes and processes that are self-determined by the students (Chen, Elliot, \& Sheldon, 2019). Compared to other educational contexts, such as MBA programs in the professional online program context, this approach to students' internal motivations should be considered to predict their perceived value, satisfaction, and loyalty toward the program (Wilkins, He, Zhu, \& Elmoshnib,2018). Therefore, this research proposes a new psychological framework for online professional programs, such as the MBA, by emphasizing a wide range of internal motivations including autonomous motivation, external motivation, need achievement, goal setting, social comparison, and reinforcement.

Second, as another theoretical contribution, this study explored which motivation is the most influential on online students' favorable outcomes for online learning program management. This research establishes an integrated model, embracing six dimensions of online learning motivation when compared to previous studies in the educational psychology and online learning literature focusing primarily on self-determination theory, goal setting, or reinforcement (Chen et al., 2019; Rogers, 2017; Yanson \& Johnson, 2016). This research additionally considers online MBA students' perceptions of social aspects in the context of an online learning environment (i.e., social comparison), although the empirical finding indicates the impact was insignificant. The social aspects need to be considered by future scholars because social interaction is one of the main reasons for pursuing a professional degree (or motivations) (Rogers, 2017). However, more interestingly, the empirical result confirms that online students' reinforcement is the most influential factor that determines loyalty toward an MBA program as well as the factors of perceived value and MBA program satisfaction. Thus, scholars in the online professional education field and online learning management need to reflect reinforcement and social comparison in addition to self-determination theory when establishing a research model. This research proposes a new avenue for formulating an online professional program and learning management model with social- and individual-oriented motivations to predict students' favorable outcomes for the online program and institutions.

\section{Practical Implications}

The empirical findings of this study are that external motivation, need achievement, and goal setting serve as indicators for evaluating benefits among online MBA students. Online program administrators and instructors need to recognize, from a managerial perspective, that internal achievement-oriented learning (e.g., psychological achievement and improvement) leads students to believe an online program is more valuable and worthwhile, regardless of whether other students talk about the program (i.e., social comparison) and how important the program is to them (i.e., autonomous 
motivation). Therefore, it is recommended that objectives, outcomes, expectations, and required prerequisite skills and knowledge are available to students. In the case of policies and expectations that are general to all courses in the program, an easily accessible resources area can be made available to students. This can be used to communicate estimated time commitment for courses, expectations for general prerequisite knowledge retained from undergraduate education, program policies, codes of conduct, technical requirements, etc. For objectives, outcomes, expectations and prerequisite skills specific to individual courses, instructors should communicate prerequisite skills, learning goals, anticipated outcomes, information about course resources, communication protocols, grading policies, and assessments in the course syllabus and within the course site of the learning management system.

Availability of this information allows the program to establish expectations and the students to create a plan for success in navigating the course. Additionally, this information is useful to the student for understanding the anticipated learning outcomes for individual courses. Furthermore, this allows students to assess the degree to which individual courses will not only provide a challenging learning environment but also determine the degree to which the course will provide opportunities to learn or reinforce skills. MBA students value course content that is related to the current business environment, such as courses, like the CPA, aligned with industry standards or credentials. Integration of ongoing topics, such as COVID-19, is perceived as challenging and relevant. Opportunities for peer-to-peer engagement, such as group projects or monitored discussion forums, can allow for active interactions. When students believe they are improved through the course and its content, they perceive the MBA program as valuable and worthwhile.

This study's empirical result reveals that the factors of need achievement and reinforcement lead to students' higher levels of MBA program satisfaction. Compared to other online learning contexts, MBA students are more likely to be satisfied with their MBA program when perceiving that they perform better than other classmates in each class. General online programs, such as online accelerated undergraduate degree programs, are generally pursued by students with similar educational backgrounds. However, online professional programs such as an MBA tend to be pursued by students from a wide range of educational backgrounds and work experiences. The online MBA students are also proud of their work experiences and previous degrees, so they are more likely to perform better than other classmates by using their own backgrounds when taking each course. Providing feedback that allows students to assess their performance relative to their peers, such a generalized, aggregated performance feedback on exams and other assessments, may allow students to feel a sense of accomplishment when their performance is relatively good. On the other hand, such aggregated feedback is also valuable to students who are performing below average. Additionally, course instructors may wish to provide students the opportunity to share their educational and work-related background via a "getting to know you" post that can be viewed by fellow classmates. This type of sharing may be valuable if students work in teams or participate in small group discussions. Opportunities to self-assess and gauge their own performance can be motivational to online MBA students. Online MBA students who perceive their program as valuable and are satisfied with it are more likely to be loyal toward their program via positive word-of-mouth, recommendations, donations, and mentorships even after graduation.

\section{Limitations and Conclusions}

This study suggests three directions for future research based on its limitations. First, although this study attempts to embrace a wide range of learning motivations when establishing a research model, one might argue that there are still unexplored motivational factors in the educational fields, such as the self-efficacy and expectancy-value constructs (Wigfield \& Eccles, 2000). Thus, future studies in the online learning context should employ various approaches (e.g., focus group interview, systemic literature review, online review analysis) to identify potential dimensions of students' learning motivations. Second, this study considers perceived value, MBA program satisfaction, and loyalty toward MBA program as 
favorable outcomes for online learning program management. However, future research needs to explore the mediating roles of other variables, such as online program identification, commitment, and trust, which have been studied in the online service management fields. This study also does not categorize the types of loyalty toward MBA programs as positive word-of-mouth, recommendation, donation, and mentorship. Future studies may look into new mediators and different types of students' loyalty behaviors to extend our research model. Finally, this study does not examine the impact of motivations on perceived value, satisfaction, and loyalty over time. Hence, future research may investigate the associations among the variables through the test-retest method (e.g., $1^{\text {st }}$ year of the MBA program vs. $2^{\text {nd }}$ year of the MBA program). That effort leads online learning program practitioners to formulate more feasible management strategies for each class.

This study has provided insight into motivational factors for students' enrollment in online MBA programs. This study demonstrates that students at a graduate level may have different goals and expectations of an online program compared to undergraduate online students. Furthermore, this study demonstrates that MBA students, enrolled in a professional graduate program, desire a high level of skill development and/or rigorous academic challenges that might be different from the expectations of students enrolled in undergraduate degree programs or other types of graduate degree programs. 


\section{References}

Al-Fraihat, D., Joy, M., Masa'deh, R., \& Sinclair, J. (2020). Evaluating e-learning systems success: An empirical study. Computers in Human Behavior, 102, 67-86.

Anderson, J. C., \& Gerbing, D. W. (1992). Assumption and comparative strengths of the two-step approach: Comment on Fornell and Yi. Sociological Methods \& Research, 20(3), 321-333.

Atkinson, J. W., \& Litwin, G. H. (1960). Achievement motive and test anxiety conceived as motive to approach success and motive to avoid failure. The Journal of Abnormal and Social Psychology, 60(1), 52-63.

Baek, T. H., \& Yoo, C. Y. (2018). Branded app usability: Conceptualization, measurement, and prediction of consumer loyalty. Journal of Advertising, 47(1), 70-82.

Bagozzi, R. P., \& Yi, Y. (1990). Assessing method variance in multitrait-multimethod matrices: The case of self-reported affect and perceptions at work. Journal of Applied Psychology, 75(5), 547-560.

Bandura, A. (1977). Self-efficacy: Toward a unifying theory of behavioral change. Psychological Review, $84(2), 191-215$

Bandura, A., \& Locke, E. A. (2003). Negative self-efficacy and goal effects revisited. Journal of Applied Psychology, 88(1), 87-99.

Barak, M., Watted, A., \& Haick, H. (2016). Motivation to learn in massive open online courses: Examining aspects of language and social engagement. Computers \& Education, 94, 49-60.

Chen, C., Elliot, A. J., \& Sheldon, K. M. (2019). Psychological need support as a predictor of intrinsic and external motivation: The mediational role of achievement goals. Educational Psychology, 39(8), 1090-1113.

Chen, K. C., \& Jang, S. J. (2010). Motivation in online learning: Testing a model of self-determination theory. Computers in Human Behavior, 26, 741-752.

Clements, A. J., \& Kamau, C. (2018). Understanding students' motivation towards proactive career behaviours through goal-setting theory and the job demands-resources model. Studies in Higher Education, 43(12), 2279-2293.

Coetzer, A. (2007). Employee perceptions of their workplaces as learning environments. Journal of Workplace Learning, 19(7), 417-434.

Deci, E. L., \& Ryan, R. M. (2000). The "what" and "why" of goal pursuits: Human needs and the selfdetermination of behavior. Psychological Inquiry, 11(4), 227-268.

Deci, E. L., \& Ryan, R. M. (2008). Self-determination theory: A macrotheory of human motivation, development, and health. Canadian Psychology/Psychologies Canadienne, 49(3), 182-185.

Deci, E. L., Vallerand, R. J., Pelletier, L. G., \& Ryan, R. M. (1991). Motivation and education: The selfdetermination perspective. Educational Psychologist, 26(3-4), 325-346.

Elliot, A. J., McGregor, H. A., \& Gable, S. (1999). Achievement goals, study strategies, and exam performance. Journal of Educational Psychology, 91(3), 549-563.

Elliot, A. J., \& Murayama, K. (2008). On the measurement of achievement goals: Critique, illustration, and application. Journal of Educational Psychology, 100(3), 613-628.

Festinger, L. (1954). A theory of social comparison processes. Human Relations, 7(2), 117-140. 
Gibbons, F. X., \& Buunk, B. P. (1999). Individual differences in social comparison: Development of a scale of social comparison orientation. Journal of Personality and Social Psychology, 76(1), 129-142.

Graves, L. M., Sarkis, J., \& Zhu, Q. (2013). How transformational leadership and employee motivation combine to predict employee proenvironmental behaviors in China. Journal of Environmental Psychology, 35, 81-91.

Hanus, M. D., \& Fox, J. (2015). Assessing the effects of gamification in the classroom: A longitudinal study on intrinsic motivation, social comparison, satisfaction, effort, and academic performance. Computers \& Education, 80, 152-161.

Inside Higher ED (November 7, 2018). Online education ascends. Retrieved from https://www.insidehighered.com/digital-learning/article/2018/11/07/new-dataonlineenrollments-grow-and-share-overall-enrollment

Kim, M., \& Kim, J. (2020). How does a celebrity make fans happy? Interaction between celebrities and fans in the social media context. Computers in Human Behavior, 111, 106419.

Kim, M., \& Thapa, B. (2018). The influence of self-congruity, perceived value, and satisfaction on destination loyalty: A case study of the Korean DMZ. Journal of Heritage Tourism, 13(3), 224236.

Konuk, F. A. (2019). The influence of perceived food quality, price fairness, perceived value and satisfaction on customers' revisit and word-of-mouth intentions toward organic food restaurants. Journal of Retailing and Consumer Services, 50, 103-110.

Lee, C. K., Yoon, Y. S., \& Lee, S. K. (2007). Investigating the relationships among perceived value, satisfaction, and recommendations: The case of the Korean DMZ. Tourism Management, 28(1), 204-214.

Lillienfeld, S. O., Lynn, S. J., Namy, L. L., \& Woolf, N. J. (2009). Psychology: From inquiry to understanding. Boston: Pearson/Allyn and Bacon.

Lin, C. H., Zhang, Y., \& Zheng, B. (2017). The role of learning strategies and motivation in online language learning: A structural equation modeling analysis. Computers \& Education, 113, 75-85.

Locke, E. A., Shaw, K. N., Saari, L. M., \& Latham, G. P. (1981). Goal setting and task performance: 19691980. Psychological Bulletin, 90(1), 125-152.

Medler, B., \& Magerko, B. (2011). Analytics of play: Using information visualization and game-play practices for visualizing video game data. Parsons Journal for Information Mapping, 3(1), 1-12.

Miller, R. B., Behrens, J. T., \& Greene, B. A. (1993). Goals and perceived ability: Impact on student valuing, self-regulation, and persistence. Contemporary Educational Psychology, 18, 2-14.

Moneta, G. B. (2011). Need for achievement, burnout, and intention to leave: Testing an occupational model in educational settings. Personality and Individual Differences, 50(2), 274-278.

Nicholls, J. G. (1984). Achievement motivation: Conceptions of ability, subjective experience, task choice, and performance. Psychological Review, 91(3), 328-346.

Nunnally, J. C. (1978). Psychometric theory. New York: McGraw-Hill.

Pham, L., Limbu, Y. B., Bui, T., Nguyen, H. T., \& Pham, H. T. (2019). Does e-learning service quality influence e-learning student satisfaction and loyalty? Evidence from Vietnam. International Journal of Educational Technology in Higher Education, 16(7), 1-26. 
Podsakoff, P. M., \& Organ, D. W. (1986). Self-reports in organizational research: Problems and prospects. Journal of Management, 12(4), 531-544.

Prebensen, N. K., \& Xie, J. (2017). Efficacy of co-creation and mastering on perceived value and satisfaction in tourists' consumption. Tourism Management, 60, 166-176.

Richter, G., Raban, D. R., \& Rafaeli, S. (2015). Studying gamification: The effect of rewards and incentives on motivation. In Gamification in Education and Business. Springer: Cham. 21-46.

Rogers, R. (2017). The motivational pull of video game feedback, rules, and social interaction: Another self-determination theory approach. Computers in Human Behavior, 73, 446-450.

Rust, R. T., Moorman, C., \& Dickson, P. R. (2002). Getting return on quality: Revenue expansion, cost reduction, or both?, Journal of Marketing, 66(4), 7-24.

Scott, A. (2018). Expectancy, goal-setting, and reinforcement: Behavioral theories and their application in the workplace. Available at SSRN 3480853.

Skinner, B. F. (1957). The experimental analysis of behavior. American Scientist, 45(4), 343-371.

Sitanggang, N., Luthan, P. L. A., \& Dwiyanto, F. A. (2020). The effect of Google SketchUp and need for achievement on the students' learning achievement of building interior design. International Journal of Emerging Technologies in Learning, 15(15), 4-19.

Sun, P. C., Tsai, R. J., Finger, G., Chen, Y. Y., \& Yeh, D. (2008). What drives a successful e-Learning? An empirical investigation of the critical factors influencing learner satisfaction. Computers \& Education, 50(4), 1183-1202.

Tsao, J. C., \& Coll, G. (2004). To give or not to give: Factors determining alumni intent to make donations as a PR outcome. Journalism \& Mass Communication Educator, 59(4), 381-392.

Tsiotsou, R. (2006). The role of perceived product quality and overall satisfaction on purchase intentions. International Journal of Consumer Studies, 30(2), 207-217.

Vansteenkiste, V., Lens, W., De Witte, H., \& Feather, N. T. (2005). Understanding unemployed people's job search behaviour, unemployment experience and well-being: A comparison of expectancy value theory and self-determination theory. British Journal of Social Psychology, 44(2), 269-287.

Wigfield, A., \& Eccles, J. S. (2000). Expectancy-value theory of achievement motivation. Contemporary Educational Psychology, 25(1), 68-81.

Wilkins, S., He, L., Zhu, L., \& Elmoshnib, M. (2018). The resilience of the MBA in emerging economies: Student motivations for wanting an MBA in China and the United Arab Emirates. Journal of Higher Education Policy and Management, 40(3), 256-271.

Wolff, F., Helm, F., \& Möller, J. (2018). Testing the dimensional comparison theory: When do students prefer dimensional comparisons to social and temporal comparisons?. Social Psychology of Education, 21(4), 875-895.

Wood, J. V. (1989). Theory and research concerning social comparisons of personal attributes. Psychological Bulletin, 106(2), 231-248.

Yanson, R., \& Johnson, R. D. (2016). An empirical examination of e-learning design: The role of trainee socialization and complexity in short term training. Computers \& Education, 101, 43-54. 
Yilmaz, R. (2017). Exploring the role of e-learning readiness on student satisfaction and motivation in flipped classroom. Computers in Human Behavior, 70, 251-260.

Zeithaml, V. A. (1988). Consumer perceptions of price, quality, and value: A means-end model and synthesis of evidence. Journal of Marketing, 52(3), 2-22.

Zhou, M. (2016). Chinese university students' acceptance of MOOCs: A self-determination perspective.

Computers \& Education, 92, 194-203.

\section{About the Author}

Dr. Minseong Kim (minseong.kim@lsus.edu) is an Assistant Professor in the Department of Management \& Marketing at Louisiana State University Shreveport. His research focuses mainly on digital learning and digital management strategies.

Dr. Tami L. Knotts (tami.knotts@Isus.edu) is the Associate Dean/ MBA Director of the College of Business and Professor in the Department of Management \& Marketing at Louisiana State University Shreveport. Her research interests are in the areas of entrepreneurship, education, and ethics.

Dr. Nancy D. Albers (nancy.albers@lsus.edu) is the Dean of the College of Business and Professor of Marketing at Louisiana State University Shreveport. Her research interests are in the areas of crosscultural values, ethics, and education. 